\title{
CONHECIMENTO ESTRATÉGICO: Caracterização e Identificação Baseada em Revisão Sistemática e Bibliométrica
}

\author{
Roberto Campos da Rocha Miranda*
}

RESUMO Este artigo apresenta a evolução dos estudos relacionados ao conhecimento estratégico, particularmente organizacional, indicando a visão ampliada das produções científicas sobre o tema, no período compreendido entre 1900 e 2018 . Essa revisão permite caracterizar e identificar esse tipo particular de conhecimento. A metodologia é descritiva e se vale da revisão sistemática e da análise bibliométrica para apresentar os dados da evolução das publicações na área. Justifica-se a realização da pesquisa em virtude de ser tema atual e de interesse sempre presente nos campos da Ciência da Informação e da Administração, em especial. Além disso, diferenciar o conhecimento estratégico como elemento fundamental para a geração de estratégias e para a tomada de decisão estratégica é particularmente importante para auxiliar na gestão da informação e do conhecimento nas organizações. A produção de trabalhos sobre conhecimento estratégico vem merecendo maior atenção nos últimos tempos e destaca a preocupação das organizações com a gestão desse ativo intangível, particularmente quanto a uso, impacto, visão, foco, pessoas e estratégia. $O$ estudo do conhecimento estratégico traz a possibilidade da discussão do tema em nível individual (além do organizacional), bem como do aprofundamento da sua diferenciação frente a outros conhecimentos dentro da organização.

Palavras-chave: Conhecimento estratégico. Gestão do conhecimento. Estratégia. Revisão Sistemática. Bibliometria.

* Doutor em Ciências da Informação pela Universidade de Brasília, Brasil. Professor do Centro Universitário Instituto de Educação Superior de Brasilia, Brasil. Analista Legislativo da Câmara dos Deputados, Brasil. Professor do Programa de Pós-graduação do Centro de Formação, Aperfeiçoamento e Treinamento da Câmara dos Deputados, Brasil.

E-mail: roberto.rocha@camara.gov.br.

\section{INTRODUÇÃO}

$\mathrm{D}$ esde a publicação dos textos de Nonaka e Takeuchi (1995) nos anos 90 do século passado, a comunidade acadêmica, particularmente voltada para as questões organizacionais, tem se debruçado sobre a gestão do conhecimento e seus desdobramentos. Porém, mais que uma simples preocupação com o tema, ou a valorização de possível modismo a ser objeto de consultorias, a questão do conhecimento, evolução do conceito de informação e dado (MIRANDA, 1999), tem sido foco de atenção por sua importância e relevância, além de promover mudanças nos processos de inovação e criação dentro das organizações.

Nesse diapasão, surge a discussão primária do que vem a ser esse conhecimento a ser gerido. Parte dos entendimentos, em gestão do conhecimento, tratam de todo o conhecimento organizacional como fonte importante para inovação. Não cabe colocação contrária, mas a sugestão de avaliar-se um conhecimento específico é fundamental para gerar na organização postura voltada à busca da vantagem competitiva sustentável apregoada por Porter (1996).

Tomando-se por referência esse contexto, este artigo se propõe a avaliar o estado geral de 
publicações sobre 'conhecimento estratégico', buscando apreender a situação de busca desse tipo de capital organizacional nas publicações científicas produzidas desde o início do século 20. Trata-se de um estudo quanta-qualitativo da produção científica sobre o tema no período que vai de janeiro de 1900 a fevereiro de 2018.

Vale destacar que o assunto tem interesse particular na gestão da informação e do conhecimento, quer seja no processo de reconhecimento e busca de informação útil à tomada de decisão, quer seja na formação de profissionais da informação aptos a lidar com tipo distinto de informação e conhecimento estratégico. Entenda-se por estratégico aqui, tudo o que se relaciona aos processos de formulação estratégica e escolha da melhor alternativa estratégica para o direcionamento de uma organização (pública ou privada). Notório salientar como motivação para a pesquisa, o documento divulgado pelo Gartner Inc. ${ }^{\circ}$ (LANEY; JAIN, 2017) sobre as tendências mundiais para os próximos anos, mormente no que tange à apropriação de domínios quanto à prática de análises avançadas de dados e informações, bem como quanto à Ciência dos Dados - entendida como o processo de obter, armazenar e tratar dados de diversos formatos (letras, números, sons, vídeos etc.) - de forma a se obter insumos para a inteligência dos negócios. No documento, afirmam os autores que nas próximas décadas, profissionais e organizações deverão aprimorar suas competências informacionais ao lidar com a inteligência dos negócios - Business Intelligence (BI) - e com recursos e orçamentos analíticos. Tais competências vão permitir o acesso a tipos de conhecimento e insights a serem extraídos dos dados. Assim, os estudos do grupo Gartner Inc. ${ }^{\circ}$ (LANEY; JAIN, 2017, p. 8) preveem:

- $\quad$ Até 2018, o aprendizado profundo (redes neurais profundas [DNN - deep neural networks]) será um componente padrão em $80 \%$ das caixas de ferramentas de cientistas de dados.

- Até 2020, mais de $40 \%$ das tarefas da ciência de dados serão automatizadas, resultando em aumento da produtividade e uso mais amplo dos recursos por cientistas de dados por cidadãos.

- $\quad$ Até 2019, o uso de linguagem natural será uma característica padrão em $90 \%$ dos BI modernos e das plataformas de busca e análise.
- Até 2019, 50\% das consultas analíticas serão geradas usando busca em linguagem natural ou voz, ou será autogerada.

- Até 2019, cidadãos-cientistas de dados superarão cientistas de dados na quantidade de análise avançada produzida. (Tradução livre)

Diante desse cenário, ainda mais válido se torna discutir o conhecimento estratégico em nível individual, grupal ou organizacional. Neste artigo, a prioridade recai sobre o último.

Desta forma, estruturam-se os temas deste paper apresentando-se inicialmente os conceitos que sustentam a revisão sistemática e a bibliometria, seguindo-se imediatamente de sua aplicação, conforme procedimentos metodológicos estabelecidos. Após a descrição dos achados, busca-se diferenciar o conceito de conhecimento estratégico para o contexto organizacional e são finalmente indicadas considerações finais que abrem possibilidade para continuação dos estudos na área.

\section{REVISÃO SISTEMÁTICA E BIBLIOMETRIA}

As revisões sistemáticas - estudos das produções científicas sobre determinado tema, em bases de dados referenciadas e em específico espaço de tempo - e de meta-análises - 'análise das análises' realizadas por pesquisadores sobre temas específicos -, têm sido foco de interesse de várias áreas de conhecimento, em virtude da possibilidade de situar a pesquisa sobre determinada questão e indicar possíveis lacunas a serem preenchidas com investigações futuras.

Assim, Moher e outros (2015) apresentam sugestão quanto aos temas que deveriam ser incluídos em uma revisão sistemática, com ênfase na indicação do título, resumo, método e resultados, com respectivos detalhamentos. Além disso, acrescentam que as revisões sistemáticas passam pelas fases de identificação - localização dos relatos afetos ao tema; seleção - separação dos relatos relevantes para a análise; elegibilidade - estudos com texto completo e passíveis de elaboração de síntese qualitativa; e, finalmente, inclusão - produção científica realmente útil e válida para se realizar a meta-análise do tema.

Tais estudos encontram eco nos trabalhos realizados em Ciência da Informação ao se valer 
da bibliometria, da cientometria e da webometria como formas de avaliação da produção cientítica. Le Coadic (2004) ressalta a importância de tais metodologias de estudo para que se tenha noção do desenvolvimento da Ciência em determinado momento da história.
Para melhor compreensão de cada forma de mensuração da produção científica, Bufrem e Prates (2005) elaboraram quadro didáticoexplicativo dos elementos que permitem a comparação entre os métodos e suas aplicações, conforme se apresenta no quadro 1.

Quadro 1 - Tipologia para definição e classificação dos termos

\begin{tabular}{|c|c|c|c|c|}
\hline $\begin{array}{c}\text { Tipologia } \\
/ / \\
\text { Subcampo }\end{array}$ & Bibliometria & Cientometria & $\begin{array}{l}\text { Informetria / } \\
\text { Infometria }\end{array}$ & Webometria \\
\hline $\begin{array}{l}\text { Objeto de } \\
\text { estudo }\end{array}$ & $\begin{array}{l}\text { Livros, } \\
\text { documentos, } \\
\text { revista, artigos, } \\
\text { autores, usuários }\end{array}$ & $\begin{array}{l}\text { Disciplinas, } \\
\text { assuntos, campos } \\
\text { científicos e } \\
\text { tecnológicos, } \\
\text { patentes, } \\
\text { dissertações e } \\
\text { teses }\end{array}$ & $\begin{array}{l}\text { Palavras, } \\
\text { documentos, } \\
\text { banco de dados, } \\
\text { comunicações } \\
\text { informais (inclusive } \\
\text { em âmbito não } \\
\text { científico) e homepage } \\
\text { na WWW } \\
\end{array}$ & $\begin{array}{l}\text { Sítios na WWW } \\
\text { (URL, título, tipo, } \\
\text { domínio, tamanho } \\
\text { e links) motores de } \\
\text { busca }\end{array}$ \\
\hline Variáveis & $\begin{array}{l}\text { Número de } \\
\text { empréstimos } \\
\text { (circulação) } \\
\text { e de citações, } \\
\text { frequência de } \\
\text { extensão de } \\
\text { frases } \\
\end{array}$ & $\begin{array}{l}\text { Fatores que } \\
\text { diferenciam as } \\
\text { subdisciplinas. } \\
\text { Como os cientistas } \\
\text { se comunicam }\end{array}$ & $\begin{array}{l}\text { Medir a recuperação, } \\
\text { relevância e } \\
\text { revocação }\end{array}$ & $\begin{array}{l}\text { Número de páginas } \\
\text { por eixo, número } \\
\text { de linhas por eixo, } \\
\text { número de links que } \\
\text { remetem ao mesmo } \\
\text { sítio, "sitações", } \\
\text { estratégias de busca } \\
\end{array}$ \\
\hline Métodos & $\begin{array}{l}\text { Ranking, } \\
\text { frequência, } \\
\text { distribuição }\end{array}$ & $\begin{array}{l}\text { Análise de } \\
\text { conjunto de } \\
\text { correspondência, } \\
\text { co-ocorrência de } \\
\text { termos, expressões }\end{array}$ & $\begin{array}{l}\text { Modelo vetor espaço, } \\
\text { modelos booleanos de } \\
\text { recuperação, modelos } \\
\text { probabilísticos, } \\
\text { linguagem de } \\
\text { processamento, } \\
\text { abordagens baseadas } \\
\text { no conhecimento, } \\
\text { tesauros }\end{array}$ & $\begin{array}{l}\text { Fator de Impacto } \\
\text { da Web (FIW), } \\
\text { densidade dos } \\
\text { links, "sitações", } \\
\text { estratégias de busca }\end{array}$ \\
\hline Objetivos & $\begin{array}{l}\text { Alocar recursos, } \\
\text { pessoas, tempo, } \\
\text { dinheiro }\end{array}$ & $\begin{array}{l}\text { Identificar } \\
\text { domínios de } \\
\text { interesse e } \\
\text { compreender } \\
\text { como e quando } \\
\text { os cientistas se } \\
\text { comunicam }\end{array}$ & $\begin{array}{l}\text { Melhorar a eficiência } \\
\text { da recuperação } \\
\text { da informação, } \\
\text { identificar relações } \\
\text { entre os diversos } \\
\text { sistemas de } \\
\text { informação }\end{array}$ & $\begin{array}{l}\text { Avaliar o sucesso de } \\
\text { determinados sítios, } \\
\text { detectar a presença } \\
\text { de instituições, } \\
\text { pesquisadores na } \\
\text { rede e melhorar } \\
\text { a eficiência dos } \\
\text { motores de busca } \\
\text { na recuperação das } \\
\text { informações }\end{array}$ \\
\hline
\end{tabular}

Fonte: Bufrem e Prates (2005, p. 16) 
Para o artigo que ora se apresenta, em função do objeto de estudo e do método, adotase a bibliometria como tipologia adequada para observar a produção científica sobre conhecimento estratégico no cenário mundial atual.

No quesito formas de representação da produção científica, lança-se mão das propostas apresentadas por Santos e Kobashi (2009), quais sejam:

- Curvas de distribuição - mostrando, por exemplo, orientadores por dissertações produzidas, ou quantidade de artigos publicados por autor e data;

- Ranking de produção - mostrando, por frequência, a produção de autores, entidades, países, etc.;

- Dendrogramas - mostrando iconicamente a distribuição de fatores e variáveis, como, por exemplo, a hierarquia de registros relacionados a determinado tema; $\mathrm{e}$,

- Grafos - mostrando o relacionamento entre autores, entidades, termos, etc.

No caso deste artigo, em razão do objeto, optou-se pela representação por tabelas, imagens, gráficos e quadros.

\section{PROCEDIMENTOS METODOLÓGICOS}

A pesquisa descritiva que se apresenta foi realizada entre os dias 14 e 16 de fevereiro de 2018, utilizando-se a pesquisa avançada dos motores de busca dos seguintes sítios:

- $\quad$ Google Trends ${ }^{\odot}$ (GOOGLE, 2018b);

- Portal de periódicos da Capes/MEC (FUNDAÇÃO CAPES, 2018); e,

- $\quad$ Google acadêmico ${ }^{\odot}$ (GOOGLE, 2018a).

O período considerado para busca foi de $1^{\circ}$ de janeiro de 1900 a 15 de fevereiro de 2018, sendo os termos buscados: conhecimento estratégico (em português), strategic knowledge (em inglês) e conocimiento estrategico (em espanhol). O outro sítio, no caso o do Google Trends ${ }^{\odot}$, foi utilizado apenas para exemplificação das tendências e o período considerado foi a partir do ano de 2004. Os termos foram buscados sempre em conjunto (com o uso de aspas), sendo desconsideradas as menções individualizadas.

Finalizando, os métodos indutivo e dedutivo foram utilizados para identificar o conhecimento estratégico, levando à formulação de conceito e de fluxo para sua identificação.

\section{DESCRIÇÃo E ANÁLISE DOS ACHADOS}

Em um primeiro momento, a investigação recaiu em se verificar a ocorrência dos termos de pesquisa como fonte de interesse geral de usuários da internet de 2004 (primeiro ano de registo do Google Trends ${ }^{\odot}$ ) até 2018, em todo o mundo, segundo informações coletadas pelo Google Trends $^{\odot}$. O resultado é apresentado na figura 1.

Figura 1 - Termos mais pesquisados desde 2004, em todo o mundo

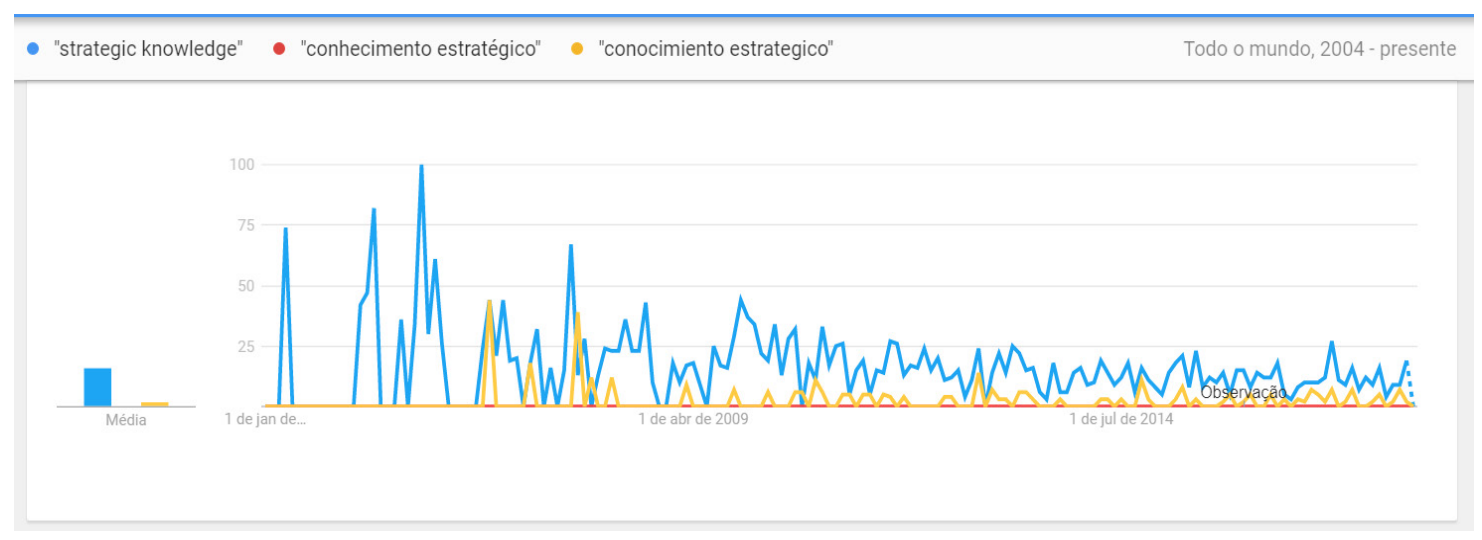

Fonte: Levantamento realizado em 13 de fevereiro de 2018 no Google Trends ${ }^{\odot}$ 
Observa-se que o termo strategic knowledge é, sem dúvida, o mais procurado, seguido de seu sinônimo em espanhol, sendo que não há qualquer expressão de busca do termo em português. Trata-se de indicativo importante que pode significar o uso do termo em acepções múltiplas - em inglês e espanhol -, levando a um maior número de ocorrências, ou a uma não associação do termo em português a algum assunto corrente. Outra observação se refere aos picos de busca entre 2004 e 2010, anos nos quais a gestão do conhecimento se tornou mais utilizada como instrumento de inovação nas organizações.

Avançando no estudo, verificou-se que apenas o termo em inglês foi buscado no mundo nos últimos 12 meses e os Estados Unidos da América o único país com interesse no assunto, conforme se verifica na figura 2, gerada pelo Google Trends $^{\odot}$. Nota-se, portanto, que o tema tem apelo na comunidade americana talvez pelo fato de que há uma tendência de preocupação constante naquele país com a busca de vantagem competitiva sustentável.

Figura 2 - Interesse no termo "strategic knowledge" por região, nos últimos 12 meses, em todo o mundo

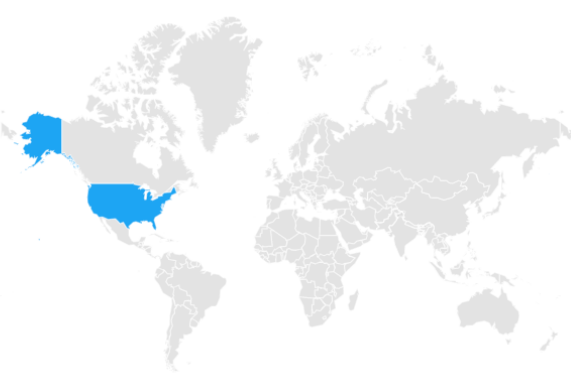

Fonte: Levantamento realizado em 13 de fevereiro de 2018 no Google Trends ${ }^{\odot}$

Ao se investigar os termos nos dois outros motores de busca escolhidos, é notória a percepção de que a produção de textos em língua inglesa é exorbitante em comparação com os termos em português e espanhol.
Tabela 1 - Quantitativo de documentos científicos que mencionam os termos

\begin{tabular}{lll}
\hline Termo & $\begin{array}{l}\text { Periódicos } \\
\text { Capes }\end{array}$ & $\begin{array}{l}\text { Google } \\
\text { Acadêmico }\end{array}$ \\
\hline $\begin{array}{l}\text { Strategic } \\
\text { Knowledge } \\
\text { Conhecimento }\end{array}$ & 3.499 & 21.600 \\
$\begin{array}{l}\text { Estratégico } \\
\text { Conocimiento }\end{array}$ & 72 & 3.020 \\
Estrategico & & 3.080 \\
\hline
\end{tabular}

Fonte: Levantamento realizado em 15 de fevereiro de 2018, no Portal de Periódicos da Capes/MEC, considerando o período de 1900 a 2018.

Dado que chama atenção no levantamento, é o fato de a proporção de textos em português e espanhol ser próxima no Google Acadêmico $^{\circledR} \mathrm{e}$ quase a metade no Portal de Periódicos da Capes (o número de ocorrências termo em espanhol é quase o dobro do encontrado para o termo em português). Uma explicação plausível é o fato de que a produção brasileira se foca, principalmente, na área de negócios (como se verifica no quadro 2) e é mais diversificada na produção em espanhol, de acordo com verificação amostral aleatória.

Por outro lado, ao se avaliar a produção científica em termos de tipo de recurso utilizado para publicação, artigos são os veículos de maior divulgação nos três idiomas considerados, conforme se observa na tabela 2. Chama a atenção o baixo número de teses que tratam do assunto. A questão que se propõe é: a academia opta pelos artigos como forma mais rápida de divulgação ou não há interesse de pesquisadores em nível de doutorado para trabalhar o assunto? O que levaria a essa baixa produção? Talvez o assunto seja um convite a um doutorado profissional, no qual aspectos teóricos se combinam com práticos para discutir a efetividade do domínio que se pretende estudar: a geração de estratégias e as decisões a elas atreladas. 
Tabela 2 - Quantitativo de documentos científicos que mencionam os termos entre 1900 e 2018

\begin{tabular}{lrrr}
\hline \multicolumn{1}{c}{ Tipo de Recurso } & $\begin{array}{c}\text { Strategic } \\
\text { Knowledge }\end{array}$ & $\begin{array}{c}\text { Conhecimento } \\
\text { Estratégico }\end{array}$ & $\begin{array}{c}\text { Conocimiento } \\
\text { Estrategico }\end{array}$ \\
\hline Artigos & 3.341 & 42 & 70 \\
Artigos de Jornal & 62 & 0 & 0 \\
Resenhas & 50 & 0 & 0 \\
Recursos Textuais & 23 & 2 & 0 \\
Teses & 12 & 1 & 1 \\
Outros & 11 & 13 & 1 \\
\hline Total & 3.499 & 48 & 72 \\
\hline
\end{tabular}

Fonte: Levantamento realizado em 14 de fevereiro de 2018, no Portal de Periódicos da Capes/MEC, considerando o período de 1900 a 2018.

Aprofundando o estudo, os tópicos mais relevantes associados ao conhecimento estratégico, de acordo com a pesquisa realizada no Portal de Periódicos da Capes/MEC, no período considerado são: Negócio; Gestão do conhecimento; Experimental / Teórico; Educação, Gestão, Formação, Regulamentos, Marketing (MB); Economia; Aprendizagem; Engenharia; Experiência / Tratamento Teórico; Psicologia; Ciência da Computação; Conhecimento; Estratégia; Solução de problemas; Gestão Estratégica; Inovação; Capital intelectual. Tais termos ratificam a associação do termo à componente organização/empresa/corporação, com baixa ênfase a outras áreas do conhecimento.

Avaliando-se, por sua expressividade nas pesquisas anteriores, o termo 'strategic knowledge', constata-se que esse aparece no contexto de publicações em diferentes idiomas, com ênfase, obviamente, em inglês, como se observa na tabela 3:
Tabela 3 - Ocorrências do temo 'strategic knowledge' em diferentes idiomas (período de 1900 a 2018)

\begin{tabular}{lcr}
\hline \multicolumn{1}{c}{ Idioma } & Ocorrências & \multicolumn{1}{c}{$\%$} \\
\hline Inglês & 3.386 & 96,77 \\
Espanhol & 48 & 1,37 \\
Português & 16 & 0,46 \\
Francês & 10 & 0,29 \\
Alemão & 7 & 0,20 \\
Outros & 32 & 0,91 \\
\hline Total & 3.499 & 100,00 \\
\hline
\end{tabular}

Fonte: Levantamento realizado em 15 de fevereiro de 2018, no Portal de Periódicos da Capes/MEC, considerando o período de 1900 a 2018.

Notável, porém, observar que o espanhol e o português são idiomas onde há textos com a menção strategic knowledge, ressaltando-se que os 32 outros idiomas nos quais o termo se apresenta incluem: japonês, lituano, chinês, polonês e italiano. Observase, ainda, que as 16 publicações em português se referem de forma diferente ao conhecimento estratégico, como se apresenta no quadro 2 . 
Quadro 2 - Relação de artigos em português que citam o termo 'strategic knowledge'

\begin{tabular}{|c|c|c|c|c|}
\hline Ano & Título & Autor & Área & Foco \\
\hline 2002 & $\begin{array}{l}\text { Probing the strategic } \\
\text { knowledge of an elite } \\
\text { volleyball setter: a case study }\end{array}$ & $\begin{array}{l}\text { Isabel Mesquita; } \\
\text { Amândio Graça }\end{array}$ & $\begin{array}{l}\text { Educação } \\
\text { Física }\end{array}$ & $\begin{array}{l}\text { Conhecimento estratégico } \\
\text { de atletas de voleibol }\end{array}$ \\
\hline 2011 & $\begin{array}{l}\text { Production of knowledge and } \\
\text { an inter-sectoral approach } \\
\text { vis-à-vis living and health } \\
\text { conditions of workers in the } \\
\text { sugarcane sector }\end{array}$ & $\begin{array}{l}\text { Carlos Minayo- } \\
\text { Gomez }\end{array}$ & Saúde & $\begin{array}{l}\text { O conhecimento } \\
\text { estratégico apropriado } \\
\text { pelos produtores de cana } \\
\text { de açúcar, auxiliando nas } \\
\text { condições de vida dos } \\
\text { trabalhadores }\end{array}$ \\
\hline 2010 & $\begin{array}{l}\text { Aprendizagem reflexiva de } \\
\text { leitura em língua estrangeira: } \\
\text { Questões relativas à construção } \\
\text { de materiais digitais para } \\
\text { acesso independente }\end{array}$ & $\begin{array}{l}\text { Denise Bértoli } \\
\text { Braga }\end{array}$ & Educação & $\begin{array}{l}\text { Conhecimento estratégico } \\
\text { relacionado às habilidades } \\
\text { de aprendizagem de } \\
\text { linguagem por meio da } \\
\text { leitura }\end{array}$ \\
\hline 2016 & $\begin{array}{l}\text { Knowledge management } \\
\text { maturity: analysis of manager's } \\
\text { perceptions of a large } \\
\text { construction company }\end{array}$ & \begin{tabular}{|l} 
Carlos \\
Henrique Cotta \\
Natale; Jorge \\
Tadeu Ramos \\
Neves; Rodrigo \\
Baroni de \\
Carvalho \\
\end{tabular} & Negócio & $\begin{array}{l}\text { Modelo de maturidade da } \\
\text { gestão do conhecimento } \\
\text { estratégico alinhado com } \\
\text { iniciativas corporativas de } \\
\text { gestão do conhecimento }\end{array}$ \\
\hline 2009 & $\begin{array}{l}\text { A Discussion about the Role of } \\
\text { Organizational Learning in the } \\
\text { Formation of Competencies }\end{array}$ & Edson de Lima & Negócio & $\begin{array}{l}\text { Relação entre } \\
\text { conhecimento estratégico } \\
\text { organizacional } \\
\text { e aprendizagem } \\
\text { organizacional }\end{array}$ \\
\hline 2005 & $\begin{array}{l}\text { Formação inicial de } \\
\text { professores: Prática docente e } \\
\text { atitudes reflexivas }\end{array}$ & $\begin{array}{l}\text { Therezinha } \\
\text { Valim Oliver } \\
\text { Gonçalves }\end{array}$ & Educação & $\begin{array}{l}\text { Construção do } \\
\text { conhecimento estratégico } \\
\text { na promoção de } \\
\text { habilidades de professores } \\
\text { reflexivos }\end{array}$ \\
\hline 2015 & $\begin{array}{l}\text { Value creation from } \\
\text { internationalization of sugar } \\
\text { cane by-products: a multi- } \\
\text { stakeholder view of artisanal } \\
\text { cachaca production }\end{array}$ & $\begin{array}{l}\text { Daiane Mulling } \\
\text { Neutzling; } \\
\text { Manoela } \\
\text { Silveira dos } \\
\text { Santos; Marcia } \\
\text { Dutra de } \\
\text { Barcellos; Anna } \\
\text { Lauren Land }\end{array}$ & Negócio & $\begin{array}{l}\text { Conhecimento estratégico } \\
\text { no processo de } \\
\text { internacionalização do } \\
\text { setor de cachaça artesanal } \\
\text { no Brasil }\end{array}$ \\
\hline 2017 & $\begin{array}{l}\text { Water management assessment } \\
\text { methodology for urban } \\
\text { planning }\end{array}$ & $\begin{array}{l}\text { Giovana Ulian; } \\
\text { Ivan Cartes; } \\
\text { Maria Lima }\end{array}$ & $\begin{array}{l}\text { Planejamen- } \\
\text { to Urbano }\end{array}$ & $\begin{array}{l}\text { Conhecimento estratégico } \\
\text { na gestão de recursos } \\
\text { hídricos }\end{array}$ \\
\hline 2016 & $\begin{array}{l}\text { Gestão do conhecimento } \\
\text { organizacional em empresa de } \\
\text { prestação de serviços técnicos }\end{array}$ & $\begin{array}{l}\text { Dusan } \\
\text { Schreiber; } \\
\text { Rafael Schaab }\end{array}$ & Negócio & $\begin{array}{l}\text { Conhecimento estratégico } \\
\text { aplicado a empresa de } \\
\text { serviços técnicos }\end{array}$ \\
\hline
\end{tabular}




\begin{tabular}{|c|c|c|c|c|}
\hline Ano & Título & Autor & Área & Foco \\
\hline 2013 & $\begin{array}{l}\text { Communities of Practice: } \\
\text { creating and sharing } \\
\text { knowledge }\end{array}$ & $\begin{array}{l}\text { Kaytson } \\
\text { Hartung; } \\
\text { Mirian Oliveira }\end{array}$ & Negócio & $\begin{array}{l}\text { Conhecimento } \\
\text { estratégico obtido pelo } \\
\text { compartilhamento em } \\
\text { ambiente de comunidades } \\
\text { de prática (CoP) }\end{array}$ \\
\hline 2015 & $\begin{array}{l}\text { Um estudo sobre a avaliação de } \\
\text { sistemas integrados de gestão } \\
\text { na região metropolitana de } \\
\text { Belo Horizonte-MG }\end{array}$ & $\begin{array}{l}\text { Warley do } \\
\text { Couto; Antônio } \\
\text { de Souza; } \\
\text { Ewerton } \\
\text { Avelar; Eloísa } \\
\text { Guimarães; } \\
\text { Luísa Gervásio }\end{array}$ & Negócio & $\begin{array}{l}\text { Conhecimento estratégico } \\
\text { obtido por meio dos } \\
\text { sistemas integrados de } \\
\text { gestão (ERP) }\end{array}$ \\
\hline 2013 & $\begin{array}{l}\text { Outcomes Of The 10th Contecsi } \\
\text { - International Conference } \\
\text { On Information Systems And } \\
\text { Technology Management }\end{array}$ & $\begin{array}{l}\text { Edson Riccio; } \\
\text { Marici Sakata; } \\
\text { Nelma } \\
\text { Valente; Ligia } \\
\text { Capobianco } \\
\end{array}$ & Negócio & $\begin{array}{l}\text { Conhecimento estratégico } \\
\text { voltado para a produção } \\
\text { de equipamentos de } \\
\text { radiofrequência }\end{array}$ \\
\hline 2016 & $\begin{array}{l}\text { The Leadership Process During } \\
\text { an Organizational Crisis }\end{array}$ & $\begin{array}{l}\text { Rodrigo } \\
\text { Bandeira-de- } \\
\text { Mello }\end{array}$ & Negócio & $\begin{array}{l}\text { Conhecimento estratégico } \\
\text { voltado para o processo de } \\
\text { liderança de uma empresa } \\
\text { brasileira do setor elétrico } \\
\text { em situação de crise }\end{array}$ \\
\hline 2014 & $\begin{array}{l}\text { Knowledge Types Used by } \\
\text { Eighth Grade Gifted Students } \\
\text { While Solving Problems }\end{array}$ & $\begin{array}{l}\text { Serdal Baltaci; } \\
\text { Avni Yildiz; } \\
\text { Bülent Güven, }\end{array}$ & Educação & $\begin{array}{l}\text { Conhecimento estratégico } \\
\text { como forma de solução } \\
\text { problemas por alunos }\end{array}$ \\
\hline 2016 & $\begin{array}{l}\text { Competencies and interactions } \\
\text { in design management }\end{array}$ & $\begin{array}{l}\text { Claudia de } \\
\text { Souza Libanio; } \\
\text { Fernando } \\
\text { Goncalves } \\
\text { Amaral } \\
\end{array}$ & Negócio & $\begin{array}{l}\text { Conhecimento estratégico } \\
\text { como competência } \\
\text { essencial na gestão de } \\
\text { profissionais de 'design' }\end{array}$ \\
\hline 2010 & $\begin{array}{l}\text { Developing competencies to } \\
\text { teach functions with GeoGebra } \\
\text { from a holistic approach: a } \\
\text { case study with prospective } \\
\text { teachers. }\end{array}$ & $\begin{array}{l}\text { Inés Gómez- } \\
\text { Chacón; Nuria } \\
\text { Prieto }\end{array}$ & Educação & $\begin{array}{l}\text { Conhecimento estratégico } \\
\text { em situações de } \\
\text { aprendizagem }\end{array}$ \\
\hline
\end{tabular}

Fonte: Levantamento realizado em 15 de fevereiro de 2018, no Portal de Periódicos da Capes/MEC, considerando o período de 1900 a 2018.

Obs.: Os artigos estão apresentados em ordem de relevância indicada pelo motor de busca na data da pesquisa. 
Reforça-se com o quadro 2 o quantitativo expressivo de artigos publicados na área de negócio (administração), com aplicações diferenciadas que vão da análise competências e liderança a contextos de tecnologia da informação e gestão do conhecimento, estas últimas consideradas áreas diretamente vinculadas aos aspectos do conhecimento estratégico organizacional, em virtude de seu valor agregado para o trato com estratégias. Verifica-se, ainda, uso do conhecimento estratégico na área de educação, com ênfase aos processos estratégicos de aprendizagem de estudantes.

\section{CARACTERIZAÇÃO E IDENTIFICAÇÃO DO CONHECIMENTO ESTRATÉGICO}

No levantamento efetuado na base de Periódicos da Capes/MEC (FUNDAÇÃO
CAPES, 2018) não foi possível localizar conceito claro de conhecimento estratégico. A menção ao termo está associada à gestão do conhecimento estratégico. Assim, dos 40 artigos mais relevantes indicados em pesquisa sobre o termo 'strategic knowledge', pode-se extrair o entendimento de alguns autores sobre o que vem a ser a 'gestão' desse conhecimento, sem necessariamente haver indicação específica do conceito de 'conhecimento estratégico', como se observa no quadro 3.

Quadro 3 - Acepções de gestão do conhecimento estratégico

\begin{tabular}{|l|l|}
\hline \multicolumn{1}{|c|}{ Conceito } & \multicolumn{1}{|c|}{ Referência } \\
\hline $\begin{array}{l}\text { O gerenciamento estratégico de conhecimento (SKM) pode ser considerado } \\
\text { como a competência de codificar e personalizar estrategicamente aspectos } \\
\text { do conhecimento (explícito e tácito) em uma organização para aumentar o } \\
\text { desempenho geral. }\end{array}$ & $\begin{array}{l}\text { Venkitachalam; } \\
\text { Willmott, 2017 }\end{array}$ \\
\hline $\begin{array}{l}\text { A SKM é usada para gerenciar lacunas e excessos de conhecimento, para } \\
\text { aprimorar o desempenho organizacional. Portanto, a SKM engloba todas as } \\
\text { técnicas que as organizações usam para alinhar as habilidades e capacidades } \\
\text { intelectuais de seus recursos humanos com seus objetivos estratégicos. }\end{array}$ & $\begin{array}{l}\text { Marques et al, } \\
2016\end{array}$ \\
\hline $\begin{array}{l}\text { A gestão estratégica do conhecimento aumenta a demanda de aprendizagem } \\
\text { permanente, enfatizando as visões e as aspirações pessoais de todos dentro da } \\
\text { organização eficiente moderna. }\end{array}$ & Petrufová, 2015 \\
\hline $\begin{array}{l}\text { Gestão do Conhecimento Estratégico (GCE) [...é...] um processo que } \\
\text { compreende a criação, a captura, a assimilação e a disseminação do } \\
\text { conhecimento estratégico organizacional. Trata-se de gerir o conhecimento que } \\
\text { se refere ao planejamento, descrição, impacto, predição, avaliação e geração } \\
\text { de estratégias. As informações estratégicas (originadas do ambiente externo à } \\
\text { organização) e não estrategicas (originadas do ambiente interno à organização) } \\
\text { formam o conhecimento estratégico, assim como o saber acumulado por } \\
\text { estrategistas e decisores no processo de formular e decidir estrategicamente. }\end{array}$ & $\begin{array}{l}\text { Miranda; Costa, } \\
\text { 2005 }\end{array}$ \\
\hline
\end{tabular}

Fonte: Levantamento realizado em 15 de fevereiro de 2018, no Portal de Periódicos da Capes/MEC, considerando os 40 artigos mais relevantes que traziam conceituação do termo 'strategic knowlege'.

Obs.: Tradução livre do autor. 
Observa-se que os três primeiros conceitos de gestão se referem à visão da gestão do conhecimento global e geral em toda a organização, sem diferenciação dos tipos de conhecimento que a organização maneja em seus diferentes níveis - estratégico, tático e operacional. A proposta aqui é, grosso modo, avaliar todos os ativos intangíveis da instituição e alinhá-los com os objetivos organizacionais.

Porém, guardando similaridade com a informação que perpassa ambientes diversos da organização e que, por isso, guarda sua caracterização relacionada com o nível a que atende (MIRANDA, 2018), advoga-se aqui a necessidade de também diferenciar a gestão do conhecimento estratégico, focando esse nas estratégias a serem apresentadas para a cúpula da organização (formulação estratégica) e a consequente escolha (decisão estratégica) de uma rota (estratégia), como apresentado no último conceito do quadro 3.

Nessa linha de raciocínio, pode-se resumidamente caracterizar o conhecimento estratégico com os seguintes atributos:

- Uso: o conhecimento estratégico é direcionado para a formulação de estratégias e para a decisão estratégica;

- Impacto: o uso do conhecimento estratégico afeta toda a organização, pois está vinculado com a direção adotada para atingir a função da organização no contexto local-mundial no qual se insere;

- Visão: o conhecimento gera e alimenta visões de futuro, acompanhando e indicando tendências, previsões ou predições que darão à organização o encaminhamento adequado à consecução de sua missão e visão estratégicas;

- Foco: o conhecimento estratégico está centrado precipuamente no ambiente externo da organização, buscando concatenar inovações e tendências do ambiente com ajustes internos que levem ao alcance dos objetivos estratégicos da organização;

- Pessoas: o interesse principal do trabalho com conhecimento estratégico está nas competências e capacidades de estrategistas em formular alternativas estratégicas e, em paralelo, nas dos decisores de alta cúpula (presidentes, diretores, CEO etc.) das organizações na tomada de decisão estratégica; e,

- Estratégia: talvez o vínculo mais importante do conhecimento estratégico, ainda que pareça óbvio, está na estratégia que, por premissa, indica, altera ou ajusta a rota da organização no sentido de que esta venha a atingir o futuro desejado e proposto em seus objetivos.

Como axioma do trabalho, arriscase a proposição de um fluxo que permita o direcionamento do pensar sobre conhecimento estratégico, no que tange à separação do conhecimento que vem a ser, ou não, efetivamente estratégico, conforme se apresenta na figura 3.

Figura 3 - Fluxo de identificação do conhecimento estratégico

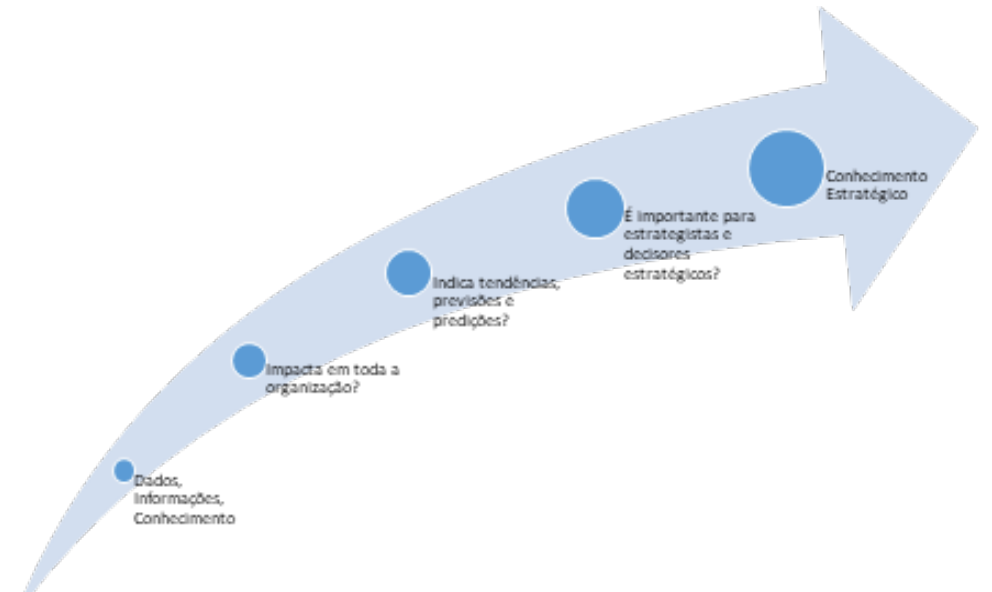

Fonte: Elaboração própria 


\section{CONSIDERAÇÕES FINAIS}

Finalizando o trabalho é possível vislumbrar que seu desenvolvimento abriu espaço para novas visões de um tema que, em princípio, tem o seu tratamento, fundamentalmente na literatura inglesa, de forma difusa e diversa, sem que se contemplem as peculiaridades do conhecimento estratégico como elemento diferenciado e focado nas estratégias.

A revisão sistemática e bibliométrica permitiu traçar um panorama geral do uso, das tendências e da compreensão de como a academia tem lidado com o termo 'conhecimento estratégico', com ênfase à sua versão em inglês, especialmente rica em produções.

Vale ressaltar que tratar todo conhecimento organizacional como único e não diferenciado pode ser um viés equivocado de premissa, por considerar todo conhecimento importante. Concorda-se com a importância de todo conhecimento no contexto organizacional, mas estabelecer prioridades e direcionamentos parecer ser um 'reducionismo' necessário para que se possam adotar práticas diferenciadas para o processo de aprimoramento do conhecimento. E assim se funda a percepção de que o conhecimento estratégico deve ser tratado de forma diversa. Os processos de conversão do conhecimento estabelecidos de forma genérica por Nonaka e Takeuchi (1995) com certeza se aplicam a esse tipo de conhecimento. Porém, a forma de atuação sobre ele seria a mesma? Estrategistas e decisores estabelecem processos de compartilhamento de conhecimento idênticos aos que se verificam entre supervisores e operários nas fábricas? Este e outros espaços surgem como possibilidade de exploração de formas de melhor aproveitamento do conhecimento estratégico para o aprimoramento de uma organização.

É assim, por exemplo, que algumas organizações contratam CEO no mercado para trazer novos rumos para a organização, ou mudar a forma como essa se direciona para a consecução de seus objetivos. Exemplificação desse processo é a substituição de técnicos de futebol nos times em atuação no Brasil. Observase que há preocupação constante em se alinhar o conhecimento estratégico acumulado dos técnicos ao objetivo final dos clubes, qual seja, a obtenção de títulos nos campeonatos diversos. Cabem questões: o conhecimento do técnico é o mesmo do jogador? Ou um tem o conhecimento estratégico e outro operacional? Reflexões que abrem espaço para estudos futuros.

Algo para ser considerado é a possibilidade de se fazer a translação da ideia de conhecimento estratégico no âmbito organizacional para uma visão pessoal e personalizada, ou seja, o conhecimento estratégico individual, aquele que todos utilizam para a definição do norte de suas existências. A discussão nesse caso pode, e, talvez, deva, considerar os aspectos cognitivos do indivíduo, sua história e suas perspectivas e desejos. Campo de interação aberto para associação entre a Administração e a Psicologia Organizacional, considerando que se buscaria efetivamente alinhamento de objetivos organizacionais e pessoais pela relação pragmática entre o conhecimento que o indivíduo detém e as possibilidades que a organização a ele dispõe.

Artigo recebido em 28/09/20I 7 e aceito para publicação em 2I/02/20 I8

\section{STRATEGIC KNOWLEDGE: Characterization and Identification Based on Systematic and Bibliometric Review}

ABSTRACT This article presents the evolution of studies related to strategic knowledge, particularly organizational, indicating the expanded view of scientific productions on the subject, in the period between 1900 and 2018. This review allows to characterize and identify that particular type of knowledge. The methodology is descriptive and uses the systematic review and bibliometric analysis to present data on the evolution of publications in the area. The realization of the research is justified by virtue of being a current topic and of interest always present in the fields of Information Science and Administration, in particular. In addition, differentiating strategic knowledge as a fundamental element for the generation of strategies and for strategic decision making is particularly important to assist in the management of information and knowledge in organizations. The production of works on strategic knowledge has been receiving more attention in recent times and highlights the concern of organizations with the management of this intangible asset, particularly in terms of use, impact, vision, focus, people and strategy. The study of strategic knowledge brings the possibility of discussing the issue at the individual level (in addition to the organizational), as well as the deepening of its differentiation compared to other knowledge within the organization.

Keywords: $\quad$ Strategic knowledge. Knowledge management. Strategy. Systematic Review. Bibliometry.

Inf. \& Soc.:Est., João Pessoa, v.28, n.1, p. 23-34, jan./abr. 2018 


\section{REFERÊNCIAS}

BUFREM, L.; PRATES, Y. O saber científico registrado e as práticas de mensuração da informação. Ciência da Informação, Brasília, v. 34, n. 2, p. 9-25, maio/ago. 2005. Disponível em: <http://www.scielo.br/pdf/ci/v34n2/28551. pdf>. Acesso em: 13 fev. 2018.

FUNDAÇÃO CAPES - Coordenação de Aperfeiçoamento de Pessoal de Nível Superior. Portal de Periódicos CAPES/MEC. Brasília, DF: Capes/Ministério da Educação. 2018. Disponível em: < http://www-periodicos-capes-gov-br.ez414. periodicos.capes.gov.br/index.php?option\%3Dcom phome\%26Itemid\%3D68\%26>. Acesso em 15 fev. 2018.

GOOGLE. Google acadêmico. 2018a.. Disponível em: <https://scholar.google. com/?oi=gsb\&hl=pt-BR>. Acesso em 15 fev. 2018.

GOOGLE. Google trends. 2018b. Disponível em: <https://scholar.google.com/?oi=gsb\&hl=ptBR>. Acesso em 15 fev. 2018.

LANEY, D.; JAIN, A. 100 Data and Analytics Predictions Through 2021. 20 June 2017. p. 1-19. United Kingdom: Gartner, Inc. 2017. Disponível em:<https://www.gartner.com/imagesrv/ media-products/pdf/tealium/Tealium-147GUGIN.pdf>. Acesso em: 15 fev. 2018.

LE COADIC, Y. F. A ciência da informação. 2. ed. Brasilia, DF: Brinquet de Lemos, 2004. 124 p.

MARQUES, C.; LEAL, C.; MARQUES, C.; CARDOSO, A. Strategic Knowledge Management, Innovation and Performance: A Qualitative Study of the Footwear Industry. Journal of the Knowledge Economy, 2016, v.7(3), p.659-675. Disponível em: <https://linkspringer-com.ez414.periodicos.capes.gov.br/ article/10.1007/s13132-015-0249-4>. Acesso em: 15 fev. 2018.

MIRANDA, R. C. R. O uso da informação na formulação de ações estratégicas pelas empresas. Ciência da Informação [on line], Brasília, v. 28, n. 3. 1999. p. 286-292. Disponível em: <http:/ / www.scielo.br/scielo.php? script=sci arttext\&pid=S0100-19651999000300006\&lng=en>. Acesso em: 15 set. 2018.
MIRANDA, R. C. R; COSTA, S. M. S. Strategic Knowledge Management: a conceptual framework. Knowledge management: nurturing culture, innovation and technology. Proceedings of the 2005 International Conference on Knowledge Management. p. 417-434. Singapore: World Scientific.

MIRANDA, R. C. R. Conhecimento estratégico. Ciência da Informação. v. 45. ed. 3. Brasília, DF: Ibict, 2018.

MOHER, D.; LIBERATI, A.; TETZLAFF, J.; ALTMAN, D. G. The PRISMA Group. Principais itens para relatar revisões sistemáticas e metaanálises: a recomendação PRISMA. Trad. Taís Freire Galvão e Thais de Souza Andrade Pansani; Retro-trad. David Harrad. Epidemiol. Serv. Saúde, 335 Brasília, 24(2): abr-jun 2015. Disponível em: <http://www.scielo.br/pdf/ress/v24n2/22379622-ress-24-02-00335.pdf>. Acesso em 26 jul. 2017.

NONAKA, I.; TAKEUCHI, H. The KnowledgeCreating Company: How Japanese Companies Create the Dynamics of Innovation. New York, NY: Oxford University Press. 1995.

PETRUFOVÁ, M. Strategic knowledge management in the armed forces academy of General M. R. Stefánik in Liptovský Mikulás, the Slovak Republic. Journal of Defense Resources Management, 2015, v.6(2), p.51-56.

PORTER, M. E. What Is Strategy? Harvard Business Review. 74, n. 6. November-December 1996. p. 61-78.

SANTOS, R. N. M.; KOBASHI, N. Y. Bibliometria, cientometria, infometria: conceitos e aplicações. Tendências da Pesquisa brasileira em Ciência da Informação, Brasília, v. 2, n. 1, p. 155-172, jan. /dez. 2009. Disponível em: <http://www.brapci. inf.br/index.php/article/view/0000007766/9f06 b999ce7cf8c5eeb0a7b691bd70e3/>. Acesso em: 13 fev. 2018.

VENKITACHALAM, K.; WILLMOTT, $\mathrm{H}$. Strategic knowledge management: insights and pitfalls. International Journal of Information Management, August 2017, v.37(4), p.313-316. Disponível em: <https://www-sciencedirectcom.ez414.periodicos.capes.gov.br/science/ article/pii/S0268401216306648?via\%3Dihub>. Acesso em: 15 fev. 2018. 